\section{A cidade, em Robert Park: entre empirismo e invençáo}

\section{The city, in Robert Park: between empiricism and invention}

VALLADARES, Licia do Prado (org.). A sociologia urbana de Robert E. Park. Rio de Janeiro, Editora UFRJ, 2018. 154 páginas.

\section{Anete B. L. Ivo \\ http://orcid.org/0000-0002-9004-3607}

Universidade Federal da Bahia (UFBA), Salvador - BA, Brasil. E-mail: anetivo@hotmail.com

DOI: $10.1590 / 3410106 / 2019$

A sociologia como ciência se constitui em autoconsciência crítica da sociedade moderna. A relação do autor com seu tempo é a chave para a leitura da rica seleção de sete textos de Robert Ezra Park sobre a cidade (dos quais, cinco inéditos no Brasil), selecionados e organizados por Licia Valladares no livro $A$ sociologia urbana de Robert Park, lançado em abril de 2018 .

Os textos de Robert Park, nessa coletânea, expressam uma tradição científica da época (início do século $\mathrm{XX}$ ), orientada para a construção do objeto sociológico. ${ }^{1}$ Neles, a ambição sociológica se traduz no esforço de levantamento e sistematização dos fenômenos empíricos da cidade moderna, entendida como instituição e organização social, mas também como organismo e fenômeno essencialmente cultural e moral, que incorpora os significados culturais e a importância da racionalidade científica sobre essa realidade, como analisa Max Weber. Licia Valladares e Michel Misse, diretor da Editora UFRJ, tiveram uma excelente ideia de reunir esses textos de Robert Park, em sua maioria desconhecidos, cuidadosamente traduzidos do inglês para o português por Wanda Brand.

A organizadora acumula uma longa e consistente tradição de pesquisas em sociologia urbana no Brasil, especialmente em temáticas relativas à moradia urbana (favela) e pobreza, com grande trânsito entre instituições acadêmicas brasileiras e francesas. Atualmente professora emérita da Université de Lille, Licia Valladares iniciou sua forma- ção acadêmica em universidades francesas, tendo concluído o doutorado em 1974, na Université de Toulouse I, e em 2001 defendido a livre-docência (Habilitation à Diriger des Recherches - HDR) na Université Lumière Lyon. O livro Passa-se uma casa (Valladares, 1978), resultante de sua tese de doutorado, produz uma inovadora crítica à política habitacional de relocação dos moradores da favela, nos anos 1970, apoiada em pesquisa empírica direta junto aos moradores e famílias incluídas naquele programa na cidade do Rio de Janeiro.

Ao lado desses estudos, Valladares tem contribuído para uma história da sociologia urbana no Brasil, com balanços sobre a contribuição de autores estrangeiros, a exemplo de Anthony Leeds, sobre as favelas do Rio de Janeiro, e o humanismo cristão de Louis-Joseph Lebret, em sua atuação para a emancipação dos povos na América Latina. Essas contribuiçóes estão detalhadas no livro $A$ invenção da favela: do mito de origem à favela.com (Valladares, 2005a), uma autorreflexão sobre seus estudos urbanos no Brasil, que avalia a ação e a influência de urbanistas, sanitaristas e agentes políticos e sociais, produtos e produtores dessa ordem social e cultural sobre a pobreza urbana (Cardoso, 2006), oferecendo grande riqueza analítica e explicitando formas de representação míticas sobre a favela.

É com esse espírito de investigação e motivada pelas formas de transferência e recepçáo da Escola de Chicago em nosso país que Valladares organizou a coletânea de textos de $A$ sociologia urbana de Robert E. Park, originada de um programa de pesquisas que ela desenvolveu em 2008 no Special Collections Research Center e na biblioteca da universidade, a Regenstein Library, sobre a obra de Park em Chicago.

A obra dá continuidade a duas produçóes anteriores de Valladares sobre Robert Park. Uma é $A$ Escola de Chicago: impacto de uma tradição no Brasil e na França (Valladares, 2005b), livro que replica uma entrevista realizada por ela e Robert Kant, em 1999, com Isaac Joseph (1943-2004), autor responsável pela introdução da Escola de Chicago na França. ${ }^{2}$ A outra é um artigo seu publicado em 2010 no Caderno $C R H^{3}{ }^{3}$

Essa coletânea com textos de Park cobre o período de 1915 a 1973 e constitui uma relevante contribuição aos estudos urbanos no Brasil, pelo 
ineditismo de uma publicação única sobre o autor, considerado por muitos e pela própria Licia, na introdução do livro, o “"pai” da sociologia urbana, o principal responsável pela chamada Escola de Chicago, e sociólogo dos mais importantes no início do século XX!" (p. 11).

Licia Valladares faz uma síntese biográfica de Robert Park na introdução (pp. 11-19), esclarecendo o leitor sobre o conjunto da obra de Park, suas influências, e apresentando os critérios de seleção dos textos que compóem a coletânea e seus conteúdos. Ao final, Valladares disponibiliza para o público brasileiro, no anexo (pp. 145-151), os resultados sistemáticos de sua pesquisa bibliográfica sobre Robert Park em livros, teses e introduções a outros livros, apresenta ainda uma cronologia biográfica de Park e uma cronologia de escritos que se referem a ele, nos Estados Unidos, no período de 1927 a 1977, e registra, ao final, as instituiçóes das quais Park participou, oferecendo aos interessados na história da sociologia e, especificamente, na história da Escola de Chicago e na do próprio autor, uma base inédita de dados sobre a trajetória biográfica e bibliográfica de Robert Park, explorados em sua pesquisa de 2008 nos Estados Unidos.

O primeiro texto da coletânea, "História de vida”, constitui uma autobiografia de Park, publicada em The American Journal of Sociology (v. 79, n. 2, p. 251-260, set. 1973), na qual o autor articula suas experiências de vida com a emergência de suas preocupaçóes sobre a cidade. O segundo texto, "A cidade: sugestôes para a investigação do comportamento humano no meio urbano" 4 - descreve a cidade "como um produto da natureza humana”, como explicita Valladares, e advoga um programa de pesquisa sobre a cidade, entendida como uma unidade geográfica e ecológica, mas também econômica, fundada na divisão do trabalho, e como área cultural estruturada em processos de vizinhança, segregação, mobilidade, relação social, controle social e ordem moral (p. 16). A terceira parte da coletânea reúne duas introduçôes de Park a livros de ex-alunos: The ghetto, de Louis Wirth, de 1929 (terceiro texto), que discute certo tipo de isolamento moral, e The gold coast and the slum, de Harvey W. Zorbaugh, também de 1929 (quarto texto), que analisa processos de autossegregação em termos de padróes de isolamento cultural (p. 17). O artigo "A cidade como laboratório social" (quinto texto), de 1929, apresenta a cidade organizada em áreas naturais, que desempenham funções na economia urbana e constituem, ao mesmo tempo, uma unidade cultural. $\mathrm{Na}$ sequência (o sexto texto da coletânea), vem o clássico artigo "A migração humana e o homem marginal", de 1928. Inspirado na figura do "estrangeiro" de Georg Simmel, Park caracteriza e define o homem marginal como um "híbrido cultural”, aquele que veio de fora para instalar-se e permanece exterior ao grupo social, expressando conflitos interculturais, a exemplo dos negros do Sul dos Estados Unidos, que vivem à margem da cultura branca. O sétimo e último texto constitui a introdução que Park escreveu, em 1942, no livro de Donald Pierson (1971 [1945]), Brancos e pretos na Bahia, também um seu ex-aluno de doutorado. ${ }^{5}$ Nele, Park discute a questão da miscigenaçáo, colaborando para compreender como a divisão de classes, em Salvador, também passa por divisóes étnicas, embora considere que "o problema racial no país [Brasil] parece ser mais 'acadêmico' que real, tendo em vista o exercício pleno de práticas religiosas de matriz africana, como o Candomblé" (Park, 1971 [1942], p. 19).

Alguns comentadores da obra de Park (Schemeil, 1983; Bourmeau, 1988) indicam a importância de sua experiência jornalística na construção de seu pensamento sociológico e destacam a importância que ele atribui à pesquisa empírica nos estudos das cidades. O próprio autor, em sua História de vida, distingue como sua experiência de jornalista o levou a assentar as bases de uma observação empírica sistemática sobre a cidade, respaldada no que ele chama de "reportagens científicas". Dessa experiência, adveio a compreensão das relações entre o jornal e a sociedade, como uma "poderosa agência para a educação e reforma” (p. 28), tema de seu doutorado em Berlim, no qual, sob a influência de Georg Simmel, analisa o jornal como fenômeno sociológico. Da prática jornalística, especialmente como editor de cidades, ele ressalta a importância da sistematização empírica na constituição do mundo real, consolidando uma postura metodológica que, segundo Becker (1996), combina, de forma eclética, métodos quantitativos e qualitativos. Para Park, "O mundo real era a experiência dos homens e mulheres reais, e não descrições abreviadas e 
taquigrafadas do que chamamos conhecimento" (p. 29), o que vai marcar fortemente sua prática científica, expressa na ideia de "Cidade como laboratório" (quinto texto).

Considero que Park, portanto, em suas reflexôes, renuncia a explicações fundadas em idealizaçóes antecipadas de pressupostos teóricos e vê a cidade como um "concreto pensado", ou seja, um conjunto de fenômenos reais, resgatado pela sistematização empírica, que cria a base para sua posterior teorização. Como analisa Rubem Oliven (2010, p. 12), Park tinha como objeto de estudo tudo o que ocorre no contexto urbano.

Essa ênfase empírica dos estudos urbanos, em Robert Park, faz da cidade uma noção aberta, sensível e vivenciada, que vai se atualizando numa decodificação criativa de várias problemáticas e manifestaçóes de fenômenos políticos, sociais, culturais e morais que ocorrem na cidade. Mesmo exibindo sua clara predileção pela cidade, seus estudos abarcam diversas dimensóes relevantes articuladas como as relaçóes raciais, a organização política da cidade, o controle social, o público, a imprensa -, que emanam dessas contribuiçôes. Suas análises sobre a conduta coletiva e o controle social e cultural remetem tanto a uma sociologia urbana como a uma ecologia social e a uma sociologia política, podendo-se concluir que contribuem, no conjunto, para a construção de uma sociologia geral.

Apreendendo a experiência urbana como síntese entre empiria e invenção, Park desenha um pensamento científico que se abre a campos relacionais complexos nas fronteiras da cidade. Da sistematizaçáo dos dados dessa realidade nasce um conhecimento que pensa os componentes fundamentais da pesquisa urbana, ao mesmo tempo que vai delineando o campo e o objeto de uma sociologia urbana e suas fronteiras.

Para finalizar, duas coisas precisam ser ditas sobre esse livro. A primeira é o fato de que algumas das contribuiçóes de Robert Park, no período de 1915 a 1973, estão agora reunidas num único volume, traduzido para o português e disponível para um amplo público no Brasil. A segunda é que os sociólogos que manejam vastas pesquisas de campo sobre fenômenos urbanos dispóem, com essa publicação, de um mapeamento sistemático das proble- máticas clássicas das pesquisas urbanas, que ajudam a decifrar e a decodificar as múltiplas dimensões da cidade como campo de pesquisa no presente.

\section{Notas}

1 Não encontrei, nos estudiosos de Robert Park, uma referência à influência de Emile Durkheim em seus escritos, mas sua compreensão de cidade e regióes como um todo funcional ou disfuncional, um organismo, uma instituição, e especialmente sua noção de "regióes morais" (áreas da cidade em que parte da população é separada das demais) me remetem à Durkheim, à sua contribuição sobre a divisão social do trabalho, os processos de diferenciação e especialização, como também à noção de vida social como fenômeno essencialmente moral. Valladares admite ser possível essa influência e lembra que Park publicou texto de Emile Durkheim no seu livro Introduction to the science of sociology (com E. W. Burguess, University of Chicago Press, 1921). Certamente Park recebe influência mais direta de G. Simmel, que refletiu sobre a sociologia e seu objeto, bem como sobre os determinantes quantitativos da vida social e exerceu grande influência nos autores da Escola de Chicago.

2 Publicada na revista $B I B$ (Rio de Janeiro, n. 49, 2000), com o título "A Escola de Chicago: entrevista com Isaac Joseph", realizada por Licia Valladares e Roberto Kant no 23 Encontro da Anpocs, parte do Acordo Capes-Cofecub entre o Programa de Antropologia e Ciência Política da Universidade Federal Fluminense - especialmente o Nufep (Núcleo Fluminense de Estudos e Pesquisas) - e as áreas de Sociologia do Iuperj e da Universidade de Paris X, Nanterre, em torno do projeto "Espaço Público, Conflitos e Democracia em uma Perspectiva Comparada”, que reuniu essas três instituiçóes desde 1998. As duas primeiras publicaçôes de Isaac Joseph no Brasil foram: o artigo "Paisagens urbanas, coisas públicas", do livro La ville sans qualités (Paris, l'Aube, 1998), reproduzido no Caderno CRH (30/31: 1-40, 1999), e o livro Erving Goffman e a microssociologia (Rio de Janeiro, Editora FGV [1998] 2000).

$3 \mathrm{O}$ artigo integrou o dossiê Periferias: questóes teóricas e de pesquisa, coordenado por mim, no Caderno CRH, n. 58.

4 Publicado anteriormente no Brasil na coletânea organizada por Guilherme Velho, O fenômeno urbano (Rio de Janeiro, Zahar, 1977).

5 A introdução de Park ao livro de Pierson foi escrita em 1942, mas a primeira edição do livro saiu em 1945, 
pela Companhia Editora Nacional. A fonte usada neste artigo refere-se à edição de 1971 .

\section{BIBLIOGRAFIA}

BECKER, Howard. (1996), "A Escola de Chicago" (Conferência). Mana, Rio de Janeiro, 2 (2): 177-188.

BOURMEAU, Sylvain. (1988), "Robert Park, journaliste et sociologue". Politix - Revue des Sciences Sociales du Politique, 1 (3-4): 50-61.

CARDOSO, Adalberto. (2006), "Metamorfoses da pobreza”. Novos estudos Cebrap, 75: 213-217.

OLIVEN, R. G. (1980), Urbanização e mudança social no Brasil. Petrópolis: Vozes. [Revisto e publicado em 2010, disponível on-line na Scielo Books].

PARK, Robert. (1915), "The city: suggestions for the investigation of human behavior in the city environment". American Journal of Sociology, 20: $577-612$.

PARK, Robert. (1971 [1942]), Introdução, in D. Pierson, Brancos e pretos na Babia: estudo de contato racial, São Paulo, Companhia Editora Nacional (col. Brasiliana, v. 241).

PARK, Robert. (1967), "A cidade: sugestôes para a investigação do comportamento humano no meio urbano", in G. Velho, O fenômeno urbano, Rio de Janeiro, Zahar.

PIERSON, Donald. (1971 [1945]), Brancos e pretos na Babia: estudo de contato racial. São Paulo, Companhia Editora Nacional (col. Brasiliana, v. 241).

SCHEMEIL, Yves. (1983), "D'une sociologie naturaliste à une sociologie politique: Robert Park". Revue Française de Sociologie, XXIV (4): 631-651.

VALLADARES, Licia. (1978), Passa-se uma casa. Rio de Janeiro, Zahar.

VALLADARES, Licia. (2005a), A invenção da favela: do mito de origem a favela.com. Rio de Janeiro, Editora FGV.
VALLADARES, Licia. (org.) (2005b), A Escola de Chicago: impacto de uma tradiçáo no Brasil e na França. Belo Horizonte, Editora UFMG.

VALLADARES, Licia. (2010), "A visita do Robert Park ao Brasil, o 'homem marginal' e a Bahia como laboratório". Caderno CRH, 23 (28): 35-49.

WIRTH, Louis. (1929), The ghetto. Chicago, University of Chicago Press.

ZORBAUGH, Harvey. (1929), The gold coast and the slum: a sociological study of Chicago's near North Side. Chicago, University of Chicago Press. 